\title{
Decline with a capital D: long-term changes in general practice consultation patterns across Australia
}

\author{
Michael J Taylor, Dell Horey, Charles Livingstone and Hal Swerissen
}

$\perp$ p he objective of Australia's Medicare program is to provide "affordable, accessible and high-quality health care". ${ }^{1}$ Over time, maintaining this objective has required reform of the Medicare Benefits Schedule (MBS) to ensure its "fitness for purpose". The website of the Australian Government Department of Health and Ageing (DoHA) lists no fewer than 27 "key MBS primary care initiatives" over the past 10 years that increased "the range of options available to GPs [general practitioners] for the provision of quality comprehensive primary care to Australians". ${ }^{2}$ Reforms have included broad approaches to increasing affordability and accessibility (eg, the Strengthening Medicare package in 2004) and special MBS item-based initiatives (eg, health assessments and care plans).

In May this year, further MBS reforms were introduced, again intended to ensure Medicare's fitness for purpose, and to address concerns that the MBS "is overly complex, encourages 'six-minute medicine' and fails to encourage preventative care, particularly for those with chronic illnesses". 3

In addition to updating previous key initiatives, the May 2010 reforms also amend Levels B, C and D consultation item descriptors, which have been unaltered since November 1993. ${ }^{4}$ The amendments are designed to encourage the use of Level C and D (long) consultation items. However, these reforms are being deployed in an environment of increasing demand and strained resources. Long consultations, the proposed cornerstone of Medicare's future preventive care agenda, have been the focus of auditing by Medicare and the Professional Services Review. ${ }^{5}$ The audit approach is controversial among GPs,, 7 and "audit anxiety" has been posited as driving down the use of long consultations by as many as one million consultations. ${ }^{8}$ In response, the federal government attributed the decline to substitution of long consultations with special Medicare items, such as those for chronic disease management, claiming that the decline was offset by "a 30.9\% rise in enhanced primary care (EPC) items". 8 The extent of the offset was disputed, with the Australian Medical Association maintaining

\section{ABSTRACT}

Objective: To determine changes in the pattern of use of standard general practice consultations, and the degree to which any changes are offset by the use of special Medicare Benefits Schedule (MBS) items.

Design, participants and setting: Population-based retrospective analysis of age- and sex-standardised Medicare claims data (1994-2009) on the utilisation of general practice standard consultations (Levels A, B, C and D) alone and in combination with health assessments and care plans and other special MBS items.

Results: Utilisation rates of Level C and D (long) consultations increased consistently from 1994 to 2004, but by 2009 a considerable decline had occurred. A reverse of this pattern was observed for Level A (short) consultations. When utilisation rates for special items and long consultations were combined, the combined utilisation rate followed an upward trend until 2007, but also declined in 2008 and 2009.

Conclusions: The decline in the use of Level $\mathrm{C}$ and $\mathrm{D}$ consultations in recent years has been dramatic and accompanied by an increase in use of Level A consultations. While the use of special items has offset the decline in long consultations, this compensating effect has weakened in the past 2 years. This pattern is at odds with health policy objectives that rely on long consultations to provide preventive care and chronic disease management. Given the current situation, the recently introduced Medicare reforms (May 2010), including changes to Levels B, C and D consultation item descriptors, may not be sufficient to change consultation patterns.

MJA 2010; 193: 80-83

For commentary, see page 84

that these statistics showed that the preventive care agenda was being undermined, not enhanced. ${ }^{8}$

Thus far, debates about changing consultation patterns have been based on comparisons of crude service volumes, whereas a longer-term, rate-adjusted approach would provide greater insight. Similarly, the federal government's concept of consultation offsetting is limited: in addition to items for chronic disease care planning, other potential MBS items creating consultation offsets include health assessments, service incentive payments and mental health care.

Our aim was to determine how consultation patterns have changed over the long term by analysing the use of the four standard general practice consultation items Levels A, B, C and D - alone and in combination with special MBS items. The broadest range of special items was used to establish whether the so-called consultation offset is sufficient to account for the decline in long consultations. Major supply-side factors that may affect consultation patterns over time, namely bulk-billing and the pop-
ulation-to-GP full-time workload equivalence (FWE) ratio, were also considered.

\section{METHODS}

\section{Data sources}

MBS data for standard consultations for the period 1994-2009 were obtained from Medicare Australia; ${ }^{9}$ during this period MBS item descriptors were unchanged. ${ }^{4}$ Data on special MBS items were obtained for 1999_ 2009. Data on the proportion of unreferred attendances that were bulk-billed by vocationally registered GPs were also obtained from Medicare Australia by financial year. ${ }^{9}$ Population data were obtained from the estimated resident population series of the Australian Bureau of Statistics (ABS) for 30 June of each year (ie, the 1994 population was the Australian estimated resident population as at 30 June 1994). ${ }^{10}$ The estimated resident populations closely approximate the total Medicare registered population. Workforce data for GPs were obtained from the DoHA website as at 30 June for each year, ${ }^{11}$ and the population-to-GP FWE ratio 


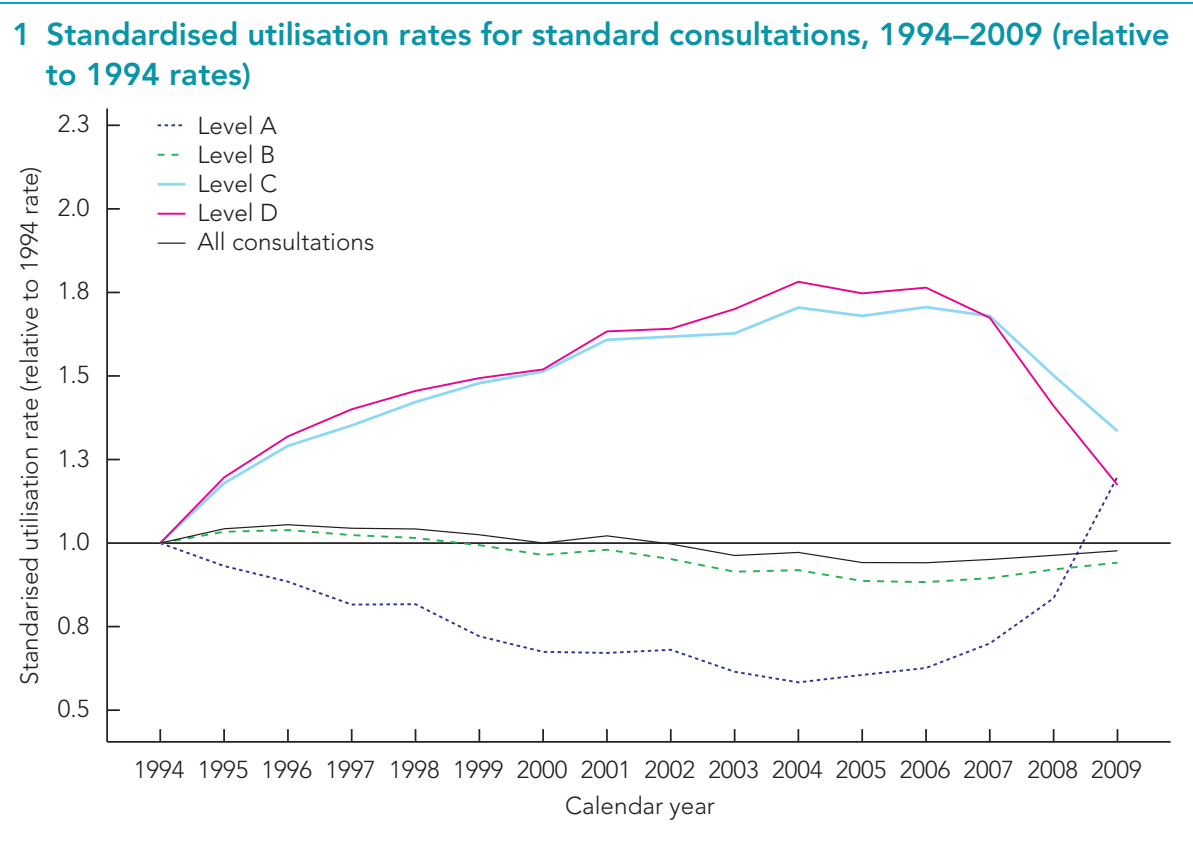

2 Actual and relative (to 1994 rates) standardised consultation utilisation rates for selected years

1994

2004

\begin{tabular}{|c|c|c|c|c|c|c|}
\hline \multirow[b]{2}{*}{ Consultation } & & & & & \\
\hline & Actual & Relative & Actual & Relative & Actual & Relative \\
\hline Level A & 106 & 1.00 & 62 & 0.58 & 127 & 1.20 \\
\hline Level B & 4015 & 1.00 & 3689 & 0.92 & 3780 & 0.94 \\
\hline Level C & 316 & 1.00 & 538 & 1.70 & 421 & 1.34 \\
\hline Level D & 29 & 1.00 & 52 & 1.79 & 35 & 1.21 \\
\hline Overall & 4466 & 1.00 & 4341 & 0.97 & 4363 & 0.98 \\
\hline
\end{tabular}

Actual $=$ age- and sex-standardised rate per 1000 population. Relative $=$ age- and sex-standardised rate pe 1000 population relative to rate observed in 1994.

was calculated using the relevant estimated resident population.

As our study used publicly available aggregate data, ethics approval was not sought.

\section{MBS items}

Analysis was confined to general practice standard consultation items for in-surgery consultations: Levels A (MBS item 3), B (item 23), $C$ (item 36) and D (item 44). For the consultation offset, special items were defined as MBS items for in-surgery consultations from Groups A14 (health assessments), A15 (chronic disease care planning), A18 (service incentive payments for diabetes, asthma, cervical screening, and the [former] mental health items), and A20 (mental health) applicable in the relevant year. For Group A18 service incentive payments, only in-surgery items at Level C and D were included; Level A and B service incentive

were included to ensure comparability wi surgery were excluded.

\section{Utilisation analysis}

Differences in rates were compared using the Fisher exact test (at 5\% significance). We used OpenEpi (Open source epidemiologic statistics for public health, version 2.3; http:// www.openepi.com) for the analysis.

\section{Consultation offset}

To account for the consultation offsets created by the MBS special items, it was assumed that these items act as direct replacements for long consultations, as suggested by the federal government. For this comparison, the utilisation rate of long consultations was calculated, and this rate was then combined with the rate for all special items to create a "long-special" consultation rate.

\section{RESULTS}

\section{Standard consultations}

The total number of standard consultations included in our study was 1.38 billion, an average annual standardised rate of 4448 consultations per 1000 population. Standardised utilisation rates for consultations, relative to 1994 rates, are shown in Box 1; Box 2 shows the rates for key time-points.

While the overall consultation utilisation rate was constant over time, considerable changes were observed for long (Level $\mathrm{C}$ and D) and Level A consultations. For long consultations, utilisation rates consistently increased between 1994 and 2004; 2004 rates were significantly higher than the base year (1994) ( $P<0.001$ for both). For Level A consultations, utilisation rates declined over the same period, and there was a slight decrease in rates for Level B consultations $(P<0.001$ for both). A reversal of these trends occurred from 2006 onwards, with strong declines in utilisation rates for long consultations, and a sharp increase in rates for Level A consultations. the previous enhanced primary care program (ie, former MBS item 720). To maintain comparability with standard consultations, case conferencing items (eg, Group A15 Subgroup 2) and items exclusively designated as out-of-

Rates for each year were calculated from MBS utilisation data and estimated resident populations. All data were age- and sex-standardised using the direct method; ${ }^{12}$ the reference population was the Australian estimated resident population for 30 June 2009. For ease of illustration, standardised rates for each calendar year were expressed relative to the standardised rate for 1994 (the base year).

\section{Consultation offset}

The utilisation rates for long consultations, alone and in combination with those for special items, are shown in Box 3. The combined utilisation rate for long-special consultations increased consistently until 2007, after which it declined significantly $(P<0.001)$. This decline cannot be attributed to any decrease in use of special items, which increased every year.

\section{Supply-side factors}

Box 4 shows the population-to-GP FWE ratio and bulk-billing levels for unreferred and enhanced primary care attendances over 

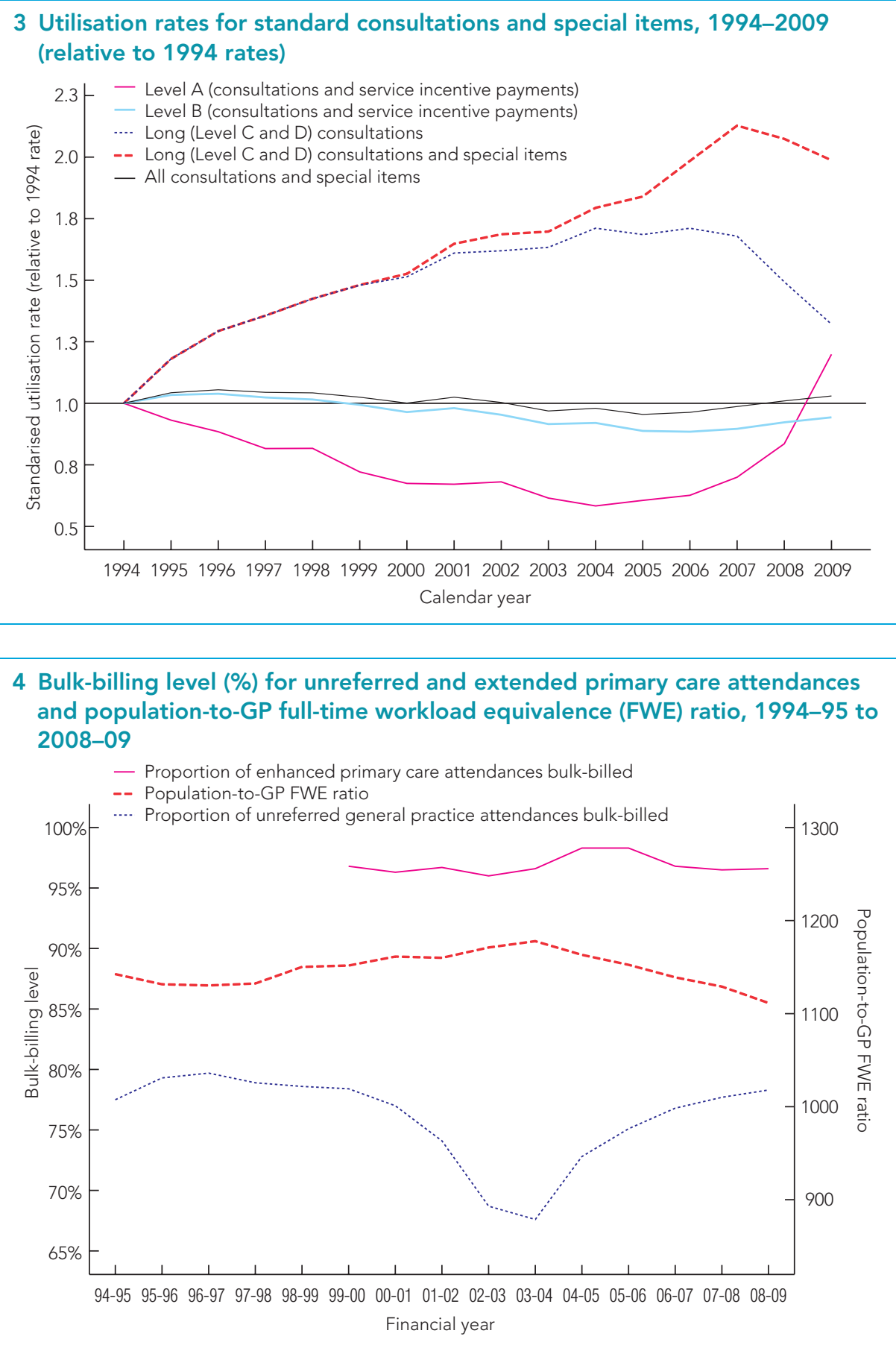

time. Only slight variation was observed in the population-to-GP FWE ratio (mean [SD], 1147 [18]), and the level of bulkbilling for enhanced primary care attendances was steady (mean [SD], 96.9\% $[0.8 \%])$. The proportion of unreferred GP attendances that were bulk-billed decreased markedly between the financial years 200203 and 2003-04, returning to the previously observed level in 2008-09. Bulk-billing was lowest (67.6\%) in 2003-04, coinciding with a (modest) peak of under- supply of GPs. As such, the changes in consultation patterns we have identified occurred during a period of relatively stable GP workforce supply, but while bulk-billing was recovering to its previous level.

\section{DISCUSSION}

The historical trend towards increased use of long consultations reflects broader changes in general practice; for example, greater involvement of GPs in complex community- based interventions, a higher prevalence of chronic diseases, and an increased number of presenting problems per GP encounter. ${ }^{13}$ However, recent years have seen a sharp reversal of this trend in consultation length, coinciding with the federal government's increasing reliance on MBS special items to guide GPs' behaviour.

Our results suggest that the federal government cannot rightfully claim, as it has done, that the decline in use of long consultations is offset by use of MBS special items. This argument did have merit up until 2007, but this is no longer the case. Similarly, "workforce supply issues" - those typically remedied by announcements of new medical school places - appear to have had little influence, given the consistency of population-to-GP FWE ratios (albeit with some change in the consultation billings that contribute to that FWE). While bulk-billing levels have now stabilised, the period of change in consultation patterns coincided with a period in which bulk-billing levels were recovering. The relationship, if any, between the restoration of bulk-billing and the shift from $85 \%$ to $100 \%$ rebates under the Strengthening Medicare program requires further investigation.

The federal government intends the May 2010 MBS reforms to encourage preventive care through the use of long consultations. These reforms are likely to influence consultation patterns, but perhaps not sufficiently to overcome other factors, and the classic friction between professional and bureaucratic interests will remain. ${ }^{14}$ Further research will be necessary to establish what effect these recent reforms will have on consultation utilisation.

In some instances, the May 2010 MBS reforms reduce the complexity of the special items (particularly the health assessments), but the fundamental problem of reliance on MBS special items remains. These items have created a greater administrative burden, both vertically (through the requirements of individual items) and horizontally (by interactions and incompatibilities between items), as illustrated by the plethora of MBS items applicable to the care of one patient with diabetes. ${ }^{15}$ Further research is needed to understand the impact of these issues on clinical practice and patient outcomes. Ultimately, administrative burden is linked to Medicare's fundamental design $^{16}$ and the continuing suitability of a payment system for episodic care in an era of preventive and chronic disease care.

The assumption that special items are substituting for long consultations is analyt- 
ically (and politically) expedient, but has significant limitations. It assumes, for example, that a health assessment is directly interchangeable with a Level C consultation, when, in reality, MBS requirements for health assessments are tightly defined, while Level C consultations involve a range of different activities. However, the special items do have considerable overlap with long consultations; for example, 63\% of problems managed in Level C consultations are chronic problems, compared with $45 \%$ in (shorter) Level B consultations. ${ }^{17}$

Another limitation of our study is that the data relate to individual services, rather than individuals and their services. Better understanding of changes in practice patterns would be obtained from a longitudinal analysis of individual patients and their service utilisation, which would map the MBS administrative burden per patient. As an example, such research could quantify double care planning under the chronic disease and mental health care programs. ${ }^{15}$ Individual patients' use of allied health services and long consultations should also be examined to determine whether care by allied health professionals creates another consultation offset. A final limitation is that the Medicare data do not include consultations under the Department of Veterans' Affairs National Treatment Account; ${ }^{9}$ however, these consultations are restricted to a small proportion of patients. ${ }^{13}$

While the utilisation patterns of individual consultation items varied over time, the overall utilisation rate was notable for its stability (Box 1). In large part, this reflects the high rate of Level $B$ consultations, which account for most general practice consultations (Box 2). However, long and special consultations, even in 2009, accounted for about $15 \%$ of all GP services ( $30 \%$ by cost).

Finally, the increase in Level A consultations should be considered carefully, especially since Level A consultations were unaltered in the May 2010 reforms. Their recent rise in utilisation may be related to an increase in patient encounters for vaccinations, prescriptions, medical certificates or test results, ${ }^{13}$ or to other factors, such as greater use of practice nurses, and, in 2009, the swine flu epidemic. However, BEACH (Bettering the Evaluation and Care of Health) data show that, while these individual reasons for encounter have increased, the number of single-problem encounters has generally decreased. ${ }^{13}$ This directly contradicts our observed rise in Level A consultations: in strict MBS terms, a Level A consultation involves "an obvious problem characterised by the straightforward nature of the task that requires a short patient history and, if required, limited examination and management". "Given that the rise in Level A consultations occurred in tandem with a decline in long consultations, further investigation of a possible relationship with administrative burden is warranted. Research is also needed on how changing consultation patterns affect patients and patient-GP relationships, particularly as patients with chronic disease perceive a "rushed GP" to be a "poor GP". 18

More Level A consultations may also provide an opportunity to consider a broader redesign of Medicare. Collectively, GPs appear to have identified - either voluntarily or under administrative duress - an increasing portion of practice with "obvious" and "straightforward" patient encounters. This may support targeted delegation of such consultations to nurse practitioners or physician assistants, which may alleviate the administrative burden on GPs and assist Medicare to realign with its objectives. The recent federal budget announcement of more funding for practice nurses ${ }^{19}$ increases the need to fully understand their role and impact on general practice.

\section{ACKNOWLEDGEMENTS}

This research was not supported by external funding. We wish to thank Ms Mary Caruana (Australian Institute for Primary Care) for editorial assistance and the peer reviewers for their suggestions. Michael Taylor would also like to thank his own GP for providing insights into the complexity of MBS billing.

\section{COMPETING INTERESTS}

None identified.

\section{AUTHOR DETAILS}

Michael J Taylor, BPharm(Hons), LLB(Hons), $\mathrm{PhD}$, Research Fellow, Australian Institute for Primary Care ${ }^{1}$

Dell Horey, BAppSc(Chem), MMedSc(Clin Epi), $\mathrm{PhD}$, Research Fellow, Faculty of Health Sciences ${ }^{1}$

Charles Livingstone, BA, MEc, PhD, Senior Lecturer, Department of Health Social Science ${ }^{2}$ Hal Swerissen, BA(Hons), GradDipPsych, MAppPsych, Pro Vice-Chancellor (Regional) and Dean of Health Sciences ${ }^{1}$

1 La Trobe University, Melbourne, VIC.

2 Monash University, Melbourne, VIC.

Correspondence:

michael.taylor@latrobe.edu.au

\section{REFERENCES}

1 Australian Government. Medicare Australia. About Medicare Australia. Canberra: Medicare Australia, 2009. http://www.medicareaustralia.gov.au/about/ whatwedo/medicare.jsp (accessed Feb 2010).
2 Australian Government Department of Health and Ageing. MBS primary care items. History of key MBS primary care initiatives 1999-2009. Canberra: DoHA, 2009. http://www.health.gov.au/internet/ main/publishing.nsf/Content/mbsprimarycare-History (accessed Feb 2010).

3 Roxon N, Minister for Health and Ageing. Medicare red tape slashed [media release]. 14 Dec 2009. Canberra: DoHA, 2009. http://www.health.gov.au/ internet/ministers/publishing.nsf/Content/mr-yr09nr-nr234.htm (accessed Feb 2010).

4 Australian Government Department of Health and Ageing. MBS Online. Medical Benefits Schedule. Canberra: DoHA, 2010. http://www.health gov.au/ internet/mbsonline/publishing.nsf/Content/Medicare-Benefits-Schedule-MBS-1 (accessed Jan 2010).

5 Professional Services Review. Report to the professions 2006-07. Canberra: Commonwealth of Australia, 2007. http://www.psr.gov.au/docs/ publications/PSR\%20Report\%20to\%20the\%20 Professions\%202006-07.pdf (accessed Sep 2009).

6 Wearne SM. An open letter to the federal Minister for Health from a general practitioner in outback Australia. Med J Aust 2009; 191: 67-69.

7 Smith P. Is PSR really on the level over C and D consults? Australian Doctor 2008; 6 May.

8 Bracey A. Audit fears undermine government's prevention push. Medical Observer 2009; 3 April.

9 Australian Government. Medicare Australia. Medicare group reports. Canberra: Medicare Australia, 2010. https://www.medicareaustralia.gov.au/statistics/mbs_group.shtml (accessed Feb 2010).

10 Australian Bureau of Statistics. Population statistics. Canberra: ABS, 2010. http://abs.gov.au/AUS STATS/abs@.nsf/web+pages/statistics? (accessed Feb 2010).

11 Australian Government Department of Health and Ageing. General practice statistics. Canberra: DoHA, 2010. http://www.health.gov.au/internet/ main/publishing.nsf/Content/General+Practice+Statistics-1 (accessed Jan 2010).

12 Daly LE, Bourke GJ. Interpretation and uses of medical statistics. 5th ed. Oxford: Blackwell Science, 2000

13 Britt H, Miller GC, Charles J, et al. General practice activity in Australia 1999-00 to 2008-09: 10 year data tables. Canberra: Australian Institute of Health and Welfare, 2009. (General practice series no. 26; AlHW Cat. No. GEP 26.) http:// www.aihw.gov.au/publications/gep/gep-26-11014/ gep-26-11014.pdf (accessed Jan 2010).

14 Alford RR. Health care politics: ideological and interest group barriers to reform. Chicago: Chicago University Press, 1975.

15 Taylor MJ, Swerissen H. Medicare and chronic disease management: integrated care as an exceptional circumstance? Aust Health Rev 2010; 34: 152-161.

16 Swerissen $H$, Taylor MJ. Reforming funding for chronic illness: Medicare-CDM. Aust Health Rev 2008; 32: 76-85.

17 Britt H, Valenti L, Miller GC, Farmer J. Determinants of GP billing in Australia: content and time. Med J Aust 2004; 181: 100-104.

18 Infante FA, Proudfoot JG, Powell Davies G, et al. How people with chronic illnesses view their care in general practice: a qualitative study. Med J Aust 2004; 181: 70-73.

19 Roxon N, Minister for Health and Ageing. More doctors and more nurses in National Health and Hospitals Network [media release]. 11 May 2010. Canberra: DoHA, 2010. http://www.health.gov.au/ internet/ministers/publishing.nsf/Content/mr-yr10nr-nr092.htm?OpenDocument\&yr $=2010 \& m t h=5$ (accessed May 2010)

(Received 3 Mar 2010, accepted 31 May 2010) 